\title{
CyberKnife Robotic Radiosurgery of Three Pancreatic Metastases of Renal Cell Cancer in One Treatment Session
}

Alexander Muacevic ${ }^{1}$, Christoph Fürweger ${ }^{2}$, Christoph Trumm ${ }^{3}$, Philipp Nuhn ${ }^{4}$, Michael Staehler ${ }^{5}$

1. European CyberKnife Center Munich, Munich, DEU 2. Chief Medical Physicist, European CyberKnife Center Munich 3. Hospital of the University of Munich 4. University Hospital of Munich 5. Urology Department, University Hospital of Munich

$\square$ Corresponding author: Alexander Muacevic, alexander.muacevic@cureus.com Disclosures can be found in Additional Information at the end of the article

\section{Abstract}

Introduction: Pancreatic metastasis accounts for $2 \%$ to $11 \%$ of all renal cell cancer (RCC) metastases. In good clinical status, patients are selected for surgery, and in more advanced disease, for systemic chemotherapy. Stereotactic radiosurgery (SRS) and stereotactic body radiation therapy (SBRT) do not play a therapeutic role so far.

Materials Methods: A 57-year-old patient was treated with CyberKnife robotic radiosurgery (CKRS) on three pancreatic RCC metastases with 22 Gy to the $75 \%$ isodose line in one treatment session. Tumor volumes were 29, 13, and 5 cc. Total non-zero beams were 121 .

Results: No immediate adverse events were detected. The patient did develop a serious complication with the occlusion of the bile duct and an infection of the implanted stent six months after the treatment that required systemic antibiotic treatment for six weeks. After that, the follow-up course was uneventful. Two and a half years after SRS, the treated tumors are no longer visible on imaging follow-up.

Conclusions: In selected cases, it may be feasible to treat multiple pancreatic metastases of RCC in only one treatment session with CyberKnife robotic radiosurgery.

Received 01/30/2014

Review began 01/30/2014

Published 02/26/2014

๑) Copyright 2014

Muacevic et al. This is an open access article distributed under the terms of the Creative Commons Attribution License CC-BY 3.0., which permits unrestricted use, distribution, and reproduction in any medium, provided the original author and source are credited.
Categories: Internal Medicine, Radiation Oncology, General Surgery

Keywords: cyberknife, pancreatic cancer, metastasis, radiosurgery, renal cell cancer

\section{Introduction}

Metastatic lesions of the pancreas are rare, accounting for approximately $2-4 \%$ of all pancreatic malignancies [1]. Renal cell carcinoma (RCC) is the most common solid tumor that metastasizes to the pancreas [1-3]. Here, we present a case of renal cell carcinoma that metastasized to the pancreas and was subsequently treated in one treatment session with robotic radiosurgery.

\section{Case Presentation}

A 57-year-old patient with a history of slowly metastasized RCC had undergone radical nephrectomy which revealed pT1b G2 L0 V0 clear cell renal cell carcinoma in 2003. Pulmonary 


\section{Cureus}

metastases subsequently appeared in 2008 and 2011, and he underwent atypical resection of the lung tumors. He was followed up without any systemic treatment. Three new pancreatic tumors in the head, body and neck with a tumor volume of 29,13 , and $5 \mathrm{cc}$, respectively, were detected eight years after surgery of the primary tumor by enhanced computed tomography (CT). On the basis of the patient's oncological background, the lack of specific tumor markers, and the hypervascular nature of the lesions in the pancreatic body, they were deemed to be metastases from RCC.

Treatment options were systemic therapy, total pancreatectomy, or local ablation. Radiosurgery was offered as an alternative, as the patient refused surgery and systemic therapy. The Interdisciplinary Tumor Board of the University of Munich Hospital approved robotic radiosurgery on an individual treatment approach.

Two gold fiducials (1x3 mm) were placed percutaneously under CT-guidance, one in the left and one the right lesion. Three targets were delineated using contrast-enhanced imaging (CT, T1 MRI). Planning target volumes (PTVs) were defined as the visible tumors in the CT scan, plus $3 \mathrm{~mm}$ isotropic expansion. CyberKnife treatment was planned with the Multiplan v3.5 software using fixed cones and one isocenter per target. Prescription dose was $22 \mathrm{~Gy}$ at the $75 \%$ isodose line, with a total PTV coverage of 95\%. Treatment was delivered with dynamic Synchrony tracking for respiratory motion compensation. For the left and right targets, the one fiducial inside each lesion was tracked. The central lesion was targeted using both fiducials. Overall treatment time was 1 hour 15 minutes.

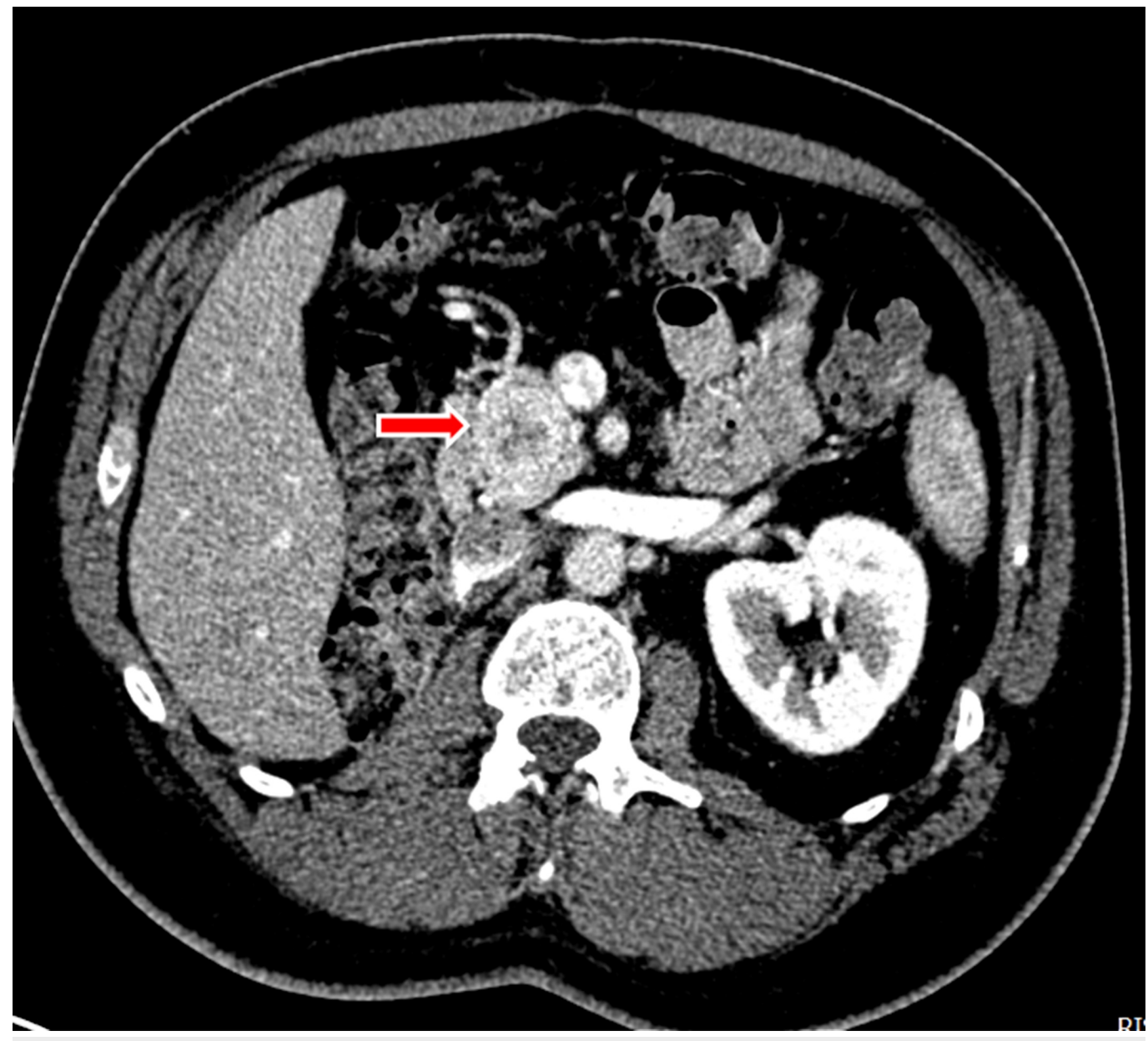

FIGURE 1: Metastasis in the pancreatic head before radiosurgery 


\section{Cureus}

Red arrow shows the largest of the three pancreatic metastases in the pancreatic head.

The patient was discharged home immediately after treatment. The initial follow-up was completely uneventful. He was evaluated every three months following treatment. Six months after treatment, the patient developed an occlusion of his bile duct and underwent a stenting procedure. Following the stent implantation, a septic syndrome was diagnosed; he was hospitalized for one week to stabilize the clinical condition. He was put on antibiotics for the following six weeks. After that, his follow-up course was uneventful. Two and a half years after the Cyberknife procedure, the patient is clinically stable and symptom-free. The three treated pancreatic tumors are no longer visible on the last computed tomography control. Furthermore, no new metastatic lesions were detected.

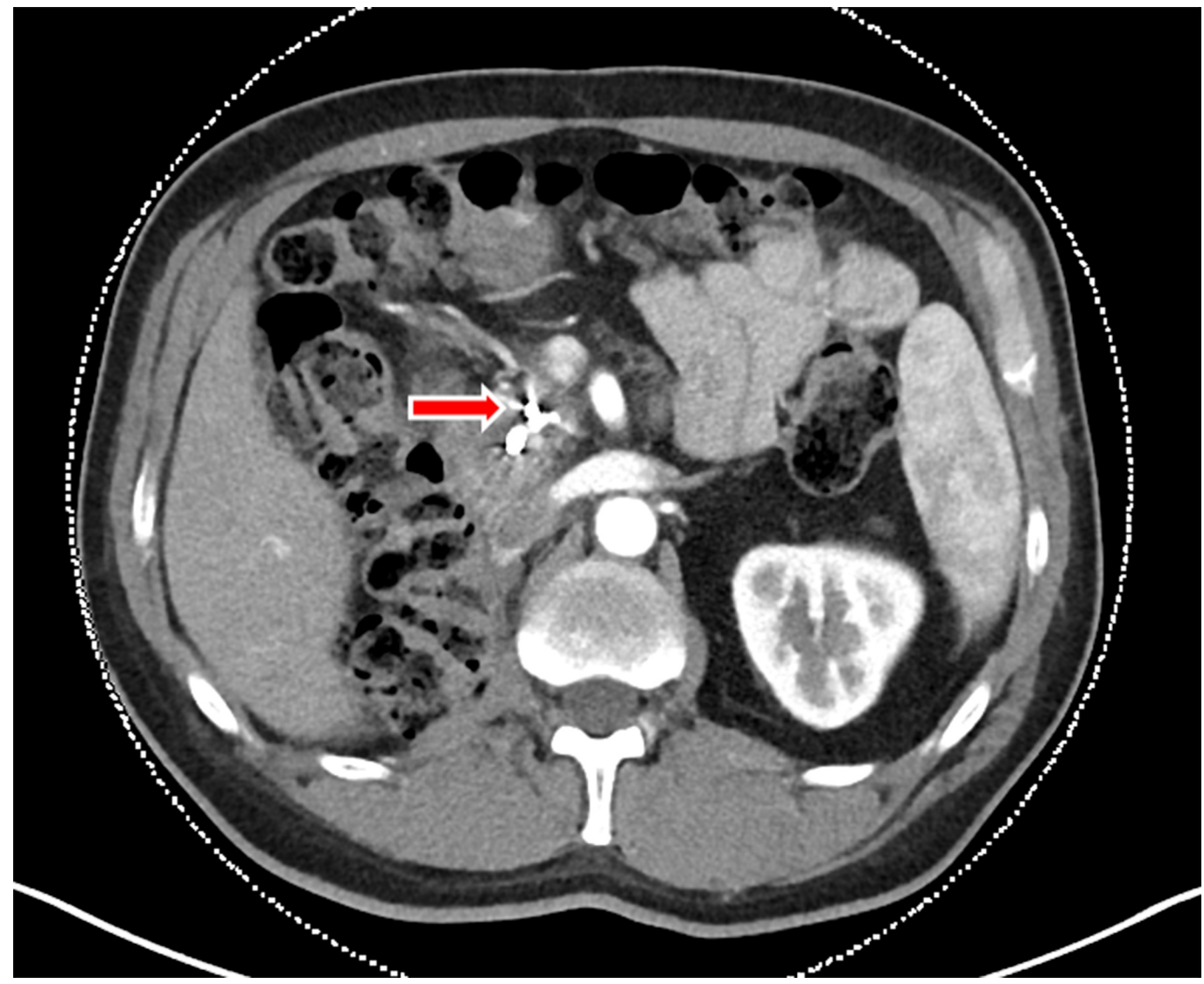

FIGURE 2: Metastasis in the pancreatic head after radiosurgery

Red arrow shows the status after tumor ablation with the fiducial markers in the middle of the pancreatic head.

\section{Discussion}

This is, to our knowledge, the first report on SRS or SBRT of pancreatic metastases of renal cell cancer. Pancreatic metastases from renal cell carcinoma are rare and usually present themselves many years after primary diagnosis [1-5]. Patients can be asymptomatic, and the diagnosis is established during follow-up imaging. In a review of 236 cases in the literature, Sellner, et al. [6] reported 35\% of these patients to be asymptomatic with others presenting with symptoms that included abdominal pain (20\%), GI bleeding due to duodenal infiltration (20\%), obstructive jaundice (9\%), weight loss (9\%), and pancreatitis and diabetes (3\% each). 
The mode of spread of renal cell carcinoma to the pancreas is controversial and can either be hematogenous or via lymphatics with direct spread to the pancreas being unusual. Spread through lymphatics may occur by retrograde lymph flow secondary to tumor infiltration of the retroperitoneal lymph nodes. Hematogenous spread may occur along the draining collateral vein of a hypervascular renal tumor with or without associated renal vein thrombosis [7].

After recent advances in pancreatic surgery, metastasectomies have become promising treatment alternatives in selected cases. Resection of a pancreatic metastasis may involve a standard pancreaticoduodenectomy or a distal pancreatectomy, depending on the location of the secondary deposit. Atypical resection of pancreatic metastasis from renal cell carcinoma, such as duodenum-preserving pancreatic head resection, middle pancreatectomy, and enucleation of the tumor, has been adopted by some authors. Atypical resection has been adopted based on the fact that these lesions are well-encapsulated [1-3, 8-11]. Five-year survival ranges from $29 \%$ to $81 \%$. Multiple metastatic lesions have a worse prognosis than solitary ones. The best treatment is described to be a R0 resection of the tumor, which is curative in most cases of solitary tumors [9-11]. Katsurakis, et al. stated that the only possible curative treatment is R0 resection [12]. Notwithstanding the favorable outcomes after surgical resection of pancreatic metastases, some patients might not qualify for surgical resection due to their clinical status. Others do not want to undergo repeated surgical resections because of previous surgeries. Particularly in RCC, ongoing systemic therapies (tyrosine kinase inhibitors) may hinder surgical interventions as these drugs should not be paused over a longer time frame. For these cases, a less invasive local therapy with comparable local tumor control may be regarded as more favorable. Saito, et al. have published results on four patients with pancreatic metastasis of renal cell carcinoma who were successfully treated with conventional radiation therapy (50 Gy, 2 fx/day) [13]. Stereotactic radiosurgery with the capabilities to apply a very high dose of radiation to a limited tumor volume has been shown to achieve this goal in different regions of the body [14]. Also, experience on the local efficacy of SRS for primary pancreatic tumors have been published [15]. However, up to now, no group has reported on SRS for RCC metastases in the pancreas. The here described case is special as multiple metastases have been treated within the pancreas with SRS in one treatment session. This became possible with the adaption of real time tumor tracking throughout the procedure. Each tumor received a high dose of radiation which could be applied precisely to the tumor volume and limit radiation exposure to the surrounding tissues, like the duodenum and stomach. Nevertheless, our patient did develop a serious complication with the occlusion of the bile duct and an infection of the implanted stent. Fortunately, the situation could be well-managed with a six week course of antibiotics. Finally, the patient did not experience any further side-effects and has been able to perform his routine job for the past two and a half years up to the present time without the necessity of additional systemic therapy.

\section{Conclusions}

We here describe a rare case with a patient harboring three pancreatic metastases of renal cancer which where all successfully treated with robotic radiosurgery in only one treatment session.

\section{Additional Information}

\section{Disclosures}

Human subjects: Consent was obtained by all participants in this study. The Interdisciplinary Tumor Board of the University of Munich Hospital issued approval N/A. Conflicts of interest: In compliance with the ICMJE uniform disclosure form, all authors declare the following:

Payment/services info: All authors have declared that no financial support was received from any organization for the submitted work. Financial relationships: All authors have declared that they have no financial relationships at present or within the previous three years with any 
organizations that might have an interest in the submitted work. Other relationships: The first author is operator of the European Cyberknife Center Munich.

\section{References}

1. Thompson LD, Heffess CS: Renal cell carcinoma to the pancreas in surgical pathology material: A clinicopathologic study of 21 cases with a review of the literature. Cancer. 2000, 89:1076-1088.

2. Sohn TA, Yeo CJ, Cameron JL, Nakeeb A, Lillemoe KD: Renal cell carcinoma metastatic to the pancreas: Results of surgical management. J Gastrointest Surg. 2001, 5:346-351.

3. Crippa S, Angelini C, Mussi C, et al.: Surgical treatment of metastatic tumors to the pancreas: A single center experience and review of the literature. World J Surg. 2006, 30:1536-1542.

4. Robbins EG, Franceschi D, Barkin JS: Solitary metastatic tumors to the pancreas: A case report and review of the literature. Amer J Gastroenterol. 1996, 91:2414-2417.

5. Niess H, Conrad C, Kleespies A, Haas F, Bao Q, Jauch KW, Graeb C, Bruns CJ: Surgery for metastasis to the pancreas: Is it safe and effective?. J Surg Oncol. 2013, 107:859-864.

6. Sellner F, Tykalsky N, de Santis M, Pont J, Klimpfinger M: Solitary and multiple isolated metastases of clear cell renal carcinoma to the pancreas: An indication for pancreatic surgery. Ann Surg Oncol. 2006, 13:75-85.

7. David AW, Samuel R, Eapen A, Vyas F, Joseph P, Sitaram V: Pancreatic metastasis from renal cell carcinoma 16 years after nephrectomy: A case report and review of the literature. Trop Gastroenterol. 2006, 27:175-176.

8. Zerbi A, Ortolano E, Balzano G, Borri A, Beneduce AA, di Carlo V: Pancreatic metastasis from renal cell carcinoma: Which patients benefit from surgical resection?. Ann Surg Oncol. 2008, 15:1161-1168.

9. Wente MN, Kleeff J, Esposito I, et al.: Renal cancer cell metastasis into the pancreas: A singlecenter experience and overview of the literature. Pancreas. 2005, 30:218-222.

10. Tuech JJ, Pessaux P, Chautard D, et al.: Results of duodenopancreatectomy for solitary pancreatic metastasis from renal cell carcinoma. J Hepatobiliary Pancreat Surg. 1999, 6:396398.

11. Kavolius JP, Mastorakos DP, Pavlovich C, Russo P, Burt ME, Brady MS: Resection of metastatic renal cell carcinoma. J Clin Oncol. 1998, 16:2261-2266.

12. Katsourakis A, Noussios G, Hadjis I, Alatsakis M, Chatzitheoklitos E: Late solitary pancreatic metastasis from renal cell carcinoma: a case report. Case Rep Med. 2012, 2012:464808. $10.1155 / 2012 / 464808$

13. Saito J, Yamanaka K, Sato M, Mori N, Sekii K, Yoshioka T, Itatani H, Nakatsuka S: Four cases of advanced renal cell carcinoma with pancreatic metastasis successfully treated with radiation therapy. Int J Clin Oncol. 2009, 14:258-61. 10.1007/s10147-008-0833-8

14. Kirkpatrick JP, Kelsey CR, Palta M, Cabrera AR, Salama JK, Patel P, Perez BA, Lee J, Yin FF: Stereotactic body radiotherapy: A critical review for non-radiation oncologists . Cancer. 2013 Dec 30, [Epub ahead of print]:10.1002/cncr.28515

15. Didolkar MS, Coleman CW, Brenner MJ, Chu KU, Olexa N, Stanwyck E, Yu A, Neerchal N, Rabinowitz S: Image-guided stereotactic radiosurgery for locally advanced pancreatic adenocarcinoma results of first 85 patients. J Gastrointest Surg. 2010, 14:1547-1559. 